\title{
Corpo, percepção e valor no pensamento curatorial contemporâneo
}

\section{Icaro Ferraz Vidal Junior}

Bolsista de pós-doutorado PNPD-Capes no Programa de Estudos Pós-Graduados em Comunicação e Semiótica da Pontifícia Universidade Católica de São Paulo. Doutor em História, História da Arte e Arqueologia pelas Université de Perpignan Via Domitia e Università degli studi di Bergamo e em Comunicação e Cultura pela Universidade Federal do Rio de Janeiro.

E-mail: vidal.icaro@gmail.com
Resumo: Este artigo parte de algumas transformações nos estatutos do corpo, do espaço e do tempo, formuladas a partir da hegemonia do cubo branco na configuração espacial das exposições de arte. Lançando mão dos conceitos de medialidade, de Müller e Felinto, de iconofagia, de Baitello Jr., e de aura, de Benjamin, propomos investigar genealogicamente as exposições de arte em suas intersecções com uma paisagem mediática mais abrangente, na qual a proliferação das imagens produz profundas alterações nos estatutos da percepção e do valor.

Palavras-chave: Curadoria; Medialidade; História das Exposições; Corpo; Aura.

\section{Body, perception and value in contemporary curatorial thinking}

Abstract: This article adopts as its starting point some transformations in the statutes of body, space and time, formulated from the hegemony of the white cube as spatial configuration of art exhibitions. Using the concepts of mediality of Müller and Felinto, iconophagy of Baitello Jr., and aura of Benjamin, we propose a genealogical research on art exhibitions at their intersections with a broader media landscape in which the proliferation of images produces profound changes in the statutes of perception and value.

Keywords: Curatorship; Mediality; History of Exhibitions; Body; Aura. 


\section{Medialidade, corpo e imagem}

Os pesquisadores Adalberto Müller e Erick Felinto iniciam um artigo no qual se propõem a apresentar um panorama de questões atualmente abordadas pela teoria da mídia alemã, colocando o leitor diante do seguinte diagnóstico: "Poucos termos são enganadoramente mais simples que 'mídia'" (MÜLLER; FELINTO, 2008: 126). Indicando, já de partida, a complexidade e o caráter polissêmico do termo, os autores introduzem o conceito de mídia tal como este opera em uma série de problemáticas que vem se delineando nas Medientheorie. Eles partem de um percurso histórico, estruturado em torno de quatro momentos decisivos: "o surgimento do alfabeto grego, a invenção da imprensa, o surgimento das mídias elétricas e eletrônicas (gramofone, cinema, tevê) e o surgimento das mídias digitais (computador, internet)" (Ibid.: 126). Tal história sublinha a importância da mídia em transformações de ordem cultural e cognitiva que vão se sedimentando e erodindo no transcorrer da história.

Nesta direção, a mídia deixa de ser compreendida, em um sentido estrito, apenas como "aparato tecnológico eletrônico-digital", e passa a englobar, em um sentido amplo, "qualquer espécie de suporte 'material' capaz de veicular sentido" (Ibid.: 129). O próprio corpo passa a ser concebido como mídia a partir de uma concepção expandida do termo, que já se encontrava formulada na classificação de Harry Pross, que, em obra

${ }^{1}$ Medienforschung, Darmstadt: Carl Kabel de $1971^{1}$, propôs uma teoria da mídia baseada em três categorias: primária, secundária e terciária. "Toda comunicação começa na mídia primária, na qual os participantes individuais se encontram cara a cara e imediatamente presentes com seu corpo; toda comunicação humana retorna a esse ponto" (PROSS, 1971 apud SANTOS, 2009: 26²).

${ }^{2}$ Em sua monografia de conclusão de curso, a autora apresenta alguns conceitos da teoria da mídia de Harry Pross e traduz integralmente algumas seções de Medienforschung, obra que permanece inédita em português.
Norval Baitello Jr. retoma esta classificação de Pross para traçar um diagnóstico que nos ajudará a formular a problemática da qual nos ocuparemos nas páginas que seguem. "De fato, a mídia primária, que se resume ao corpo e suas linguagens naturais, tem estado em baixa diante do poder econômico e político da comunicação em grandes escalas por aparatos cada vez mais potentes e sofisticados" (BAITELLO JR., 2014: 55). Em sua leitura das teses de Pross, Baitello Jr. acentua uma dimensão do corpo nos processos comunicativos que, embora formulada por Pross - por exemplo, quando lemos na citação acima que "toda comunicação retorna a esse ponto [o corpo]" -, adquire maior relevo a partir da tese da iconofagia e, mais precisamente, do diagnóstico de uma perda da dimensão proprioceptiva da experiência, em estreita relação com a proliferação das imagens mediáticas.

Este diagnóstico de Baitello Jr. será a fonte de ignição para nossa reflexão acerca do estatuto do corpo em meio à experiência de fruição estética que tem lugar nas exposições de arte. A questão que nos colocamos consiste em saber se, em uma paisagem saturada de imagens mediáticas, que não cessam de nos devorar enquanto nós as devoramos, haveria alguma brecha através da qual as artes visuais poderiam mobilizar outros agenciamentos espaço-temporais, corporais e afetivos, restituindo ao espectador a propriocepção e, através dela, a experiência de um corpo presente diante de uma obra de arte?

Em A carta, o abismo, o beijo: os ambientes de imagens entre o artístico e o mediático, de 2018, Baitello Jr. cria um filtro a partir do qual apresenta os ensaios reunidos no volume. Tal filtro - a noção de "objetos artístico-mediáticos" -, assim como sua perspectiva ambiental ou ecológica sobre as imagens, fornecem mais um importante princípio para as hipóteses que aventamos neste artigo. $\mathrm{O}$ autor esclarece:

A expansão do espectro das imagens mediáticas a partir de fins do século XIX e sua explosão na segunda metade do século XX já não permitem a leitura puramente estetizante da criação artístico-mediática, no mundo das imagens que passaram a se produzir e reproduzir em dimensões e proporções inauditas. Mesmo aquelas imagens que se querem exclusivamente artísticas não serão compreendidas assim, pois habitam os ambientes mediáticos. E são os ambien- 
tes mediáticos que fornecem os parâmetros para nossos olhares, educam e moldam mesmo nossa mirada. E é o olhar quem constrói a imagem. Qualquer olhar que obedeça aos parâmetros unicamente estéticos perderá o mais instigante e o mais vigoroso dos objetos e imagens contemporâneos, sua lida com a grande exigência de exposição que o universo mediático oferece em todas as suas formas. (BAITELLO JR., 2018: 14)

À questão do corpo como mídia primária e do ingresso das imagens artísticas em ambientes mediáticos, acrescentamos uma última problemática: aquela condensada na noção de "materialidades da comunicação". Esta noção não constitui propriamente uma novidade, embora atualmente englobe formulações e abordagens dos efeitos das materialidades da mídia dotadas de grande originalidade. Hans Ulrich Gumbrecht, em Produção de presença: o que o sentido não consegue transmitir (2010), diagnostica a hegemonia do paradigma hermenêutico/interpretativo nas ciências humanas, e apresenta algumas noções que propõem uma oscilação entre os pólos do sentido e da presença, o que, segundo o autor, definiria a própria experiência estética. Com esta obra, Gumbrecht (2010: 15)

assume o compromisso de lutar contra a tendência da cultura contemporânea de abandonar, e até esquecer, a possibilidade de uma relação com o mundo fundada na presença. Mais especificamente, assume o compromisso de lutar contra a diminuição sistemática de presença e contra a centralidade incontestada da interpretação nas disciplinas do que chamamos "Artes e Humanidades". Se é verdade que se pode descrever a moderna cultura ocidental (incluindo nela a cultura contemporânea) como um processo gradual de abandono e esquecimento da presença, também é verdade que alguns "efeitos especiais" produzidos hoje pelas tecnologias de comunicação mais avançadas podem revelar-se úteis no re-despertar do desejo de presença. Em última análise, o que este livro defende é uma relação com as coisas do mundo que possa oscilar entre efeitos de presença e efeitos de sentido

A hegemonia do sentido sobre a presença, para colocarmos a questão nos termos de Gumbrecht, sintomatiza, ao mesmo tempo em que reitera, alguns princípios que alicerçam a crença moderna e ocidental em uma humanidade soberana, na qual os sujeitos se vêem como observadores exteriores às coisas do mundo, que são reduzidas a objetos de percepção e conhecimento. A negligência da materialidade da experiência em favor dos sentidos (mais ou menos herméticos) que seriam acessados por indivíduos interpretantes assegura, no caso de uma experiência no campo da arte, um elevado nível de controle e uma separação nítida dos papéis dos artistas e do público. Este deveria interpretar as criações daqueles.

A noção de medialidade e as reflexões acerca das materialidades da comunicação, por sua vez, deslocam "o foco tradicional de nossas investigações, da busca do sentido para a determinação das condições permitindo a emergência do sentido" (MÜLLER; FELINTO, 2008: 131, grifo dos autores). Por causa disso, esta perspectiva vem integrar nosso escopo de reflexão, juntamente com aquela formulada por Harry Pross do corpo como mídia primária, com o diagnóstico de Baitello Jr. da perda do corpo diante das imagens mediáticas e com a reflexão deste último sobre o trânsito das imagens artísticas pelos ambientes mediáticos. Nossa aposta é que estas reflexões nos permitam avançar sobre o campo emergente das pesquisas e das práticas curatoriais desde uma perspectiva que se situa fora das abordagens mais recorrentes, que tendem a privilegiar a crítica estética, historiográfica ou institucional.

Na esteira de um movimento realizado por Hans Belting $(2012,2014)$, de reflexão sobre a imagem para além da arte, propomos retomar um topos fundamental - e, talvez, fundador - dos estudos sobre curadoria e história das exposições: a configuração do dispositivo do cubo branco como modelo expográfico hegemônico, e sua crítica a partir dos ensaios de Brian O'Doherty (2012). Nossa argumentação, entretanto, buscará dar consistência a uma leitura mediática das exposições e, simultaneamente, introduzir as transformações na arquitetura expográfica em um 
contexto histórico e social mais amplo, no qual se desenvolveram os ambientes mediáticos e o estatuto das imagens artísticas viu-se tensionado por uma série de transformações que não estavam restritas aos domínios da arte e da estética. Dito de outro modo, propomos pensar a emergência e hegemonia do cubo branco em meio às mutações que, na passagem do século XIX para o século XX, incidiram $\mathrm{e}$ reverberaram sobre todo um ecossistema das imagens.

\section{A exposição como mídia}

A recepção crítica e historiográfica das artes visuais frequentemente negligenciou o contexto material no qual o público, especializado ou não, entrou em contato com as obras de arte propriamente ditas, geralmente o contexto expositivo. Recentemente, o desenvolvimento de um novo domínio de pesquisa no âmbito da História da Arte, comprometido com a escrita de uma história das exposições (CYPRIANO; OLIVEIRA, 2017), vem tentando remediar esta espécie de idealismo descorporificado, que atravessa uma historiografia da arte na qual as obras de arte são abordadas como unidades identitárias, cerradas sobre si mesmas no caso de uma perspectiva formalista; ou herdeiras de temas e estilos atribuídos a obras historicamente anteriores, no caso de uma abordagem histórica. Ora, nem mesmo no interior do ateliê do artista, antes de qualquer exposição pública, a obra de arte conheceu uma existência isolada das demais imagens do mundo, de seu espaço circundante, e dos corpos daqueles que a viram antes que ela chegasse ao espaço expositivo.

Retomaremos algumas questões caras às reflexões sobre as práticas curatoriais contemporâneas e a reconfiguração do sistema da arte a partir deste processo de autoconscientização, por parte da história das exposições, da importância do contexto no qual o encontro do público com as obras de arte tem lugar (LAFUENTE et al., 2017: 15). O movimento que vem sendo criticamente operado pela escrita das histórias das exposições, além de introduzir como objetos de reflexão uma série de novos atores - a instituição, o arquiteto, os displays etc. -, cria uma brecha através da qual podemos problematizar a hegemonia contemporânea da visualidade, reinvestindo a plurissensorialidade da experiência corporificada de presença como chave para pensar os processos de produção de sentidos e de subjetividades no contexto das exposições de arte.

Publicados pela revista Artforum entre 1976 e 1981, os ensaios que compõem o volume Inside the white cube: the ideology of the gallery space, de Brian O'Doherty (2012), tornaram-se referências fundamentais na literatura contemporânea sobre artes visuais. As análises de O'Doherty foram seminais na constituição da exposição como um objeto de pesquisa legítimo, relevante e complexo, a ser abordado a partir da heterogeneidade de elementos que a constitui, e não recalcada em favor de interpretações dos sentidos que emergiriam da reunião de um determinado conjunto de obras de arte.

Por um lado, o cerne do diagnóstico de O'Doherty pode ser pensado em estreita relação com o contexto epistemológico do pós-estruturalismo, que também alimentou as reflexões em torno da noção de medialidade e das materialidades da comunicação. Além disso, o pensamento pós-estruturalista forjou a noção de dispositivo, a fim de dar conta de um modo de operação segundo o qual um conjunto de elementos heterogêneos, ao se articular de determinada maneira, desencadeia efeitos, produzindo modos de ver e de ser que são irredutíveis à soma de suas partes. Os ensaios de O'Doherty debruçam-se sobre uma configuração espacial específica, que se tornou hegemônica nas exposições de arte moderna e contemporânea e dá título ao seu livro: o cubo branco. A galeria de arte tem seu espaço descrito pelo autor nos seguintes termos:

Uma galeria é construída baseada em leis rigorosas, como aquelas que orientavam a edificação de uma igreja medieval. Porque o mundo externo deve permanecer fora, em geral as janelas são seladas; as paredes são pintadas de 
branco; o teto torna-se fonte de luz. O piso de madeira é tão polido que percebe-se distintamente os rumores dos passos, ou é coberto por um tapete que amortece aquele som, permitindo pousar os pés enquanto os olhos tomam de assalto a parede. (O'DOHERTY, 2012: 22, tradução nossa)

O'Doherty empreende sua leitura do cubo branco e o define como sendo um dispositivo capaz de produzir determinados efeitos sobre a experiência do público com a obra e sobre o próprio estatuto social da arte. Além de demonstrar que esta configuração arquitetônica dos espaços expositivos resulta de um processo complexo de transformações históricas, estéticas e institucionais, o autor dá pistas importantes sobre o lugar do corpo do espectador no interior deste sistema.

Este espaço sem sombra, branco, limpo, artificial é dedicado à tecnologia da estética. As obras de arte são montadas, suspensas, distanciadas para serem estudadas. Suas superfícies intactas não são afetadas pelo tempo e pelas suas vicissitudes. A arte existe em uma espécie de eternidade da exposição e embora se distingam diversas características "de época" (o tardomodernismo), não conhece tempo. Esta eternidade confere à galeria um status comparável ao limbo; para acessá-la é preciso estar morto. Com efeito, a presença daquele estranho móvel, nosso corpo, parece supérflua, é uma intrusão. $O$ espaço faz pensar que enquanto o olho e a mente são bem aceitos, os corpos não são, ou são tolerados apenas como manequins sinestésicos a serem submetidos a uma análise ulterior. Este paradoxo cartesiano é reforçado por um dos emblemas de nossa cultura visual: a foto da instalação sem ninguém, na qual o observador foi finalmente eliminado. (Ibid.: 23)

Apesar de ter se tornado o regime expográfico hegemônico quando pensamos nas exposições de arte moderna e contemporânea, a investida das disciplinas históricas sobre o campo das exposições nos mostram que nada há de natural ou funcional no cubo branco. Este dispositivo se assenta sobre uma série de transformações no próprio estatuto da representação pictórica que, na medida em que adquire consciência de sua superficialidade bidimensional, já não consegue ser contida apenas por uma moldura, por mais ornamentada que ela seja. Antes da invenção do cubo branco, os salões expunham muitas pinturas, dotadas de espessas e imponentes molduras, sobre uma mesma parede que quase não se via (Figura 3). Os limites definidos por cada moldura operavam como janelas para uma cena ou paisagem cuja composição exercia uma força centrípeta, trazendo o olhar do espectador para o centro do quadro.

O escopo deste artigo não comporta muitas das minúcias que marcaram o processo histórico de transformação dos modos de expor e de ver obras de arte. Os salões do século XIX, cujas paredes eram praticamente revestidas por pinturas ricamente molduradas, e o asséptico cubo branco constituem os dois nós em torno dos quais centramos nosso esforço genealógico. Como oportunamente pontua O'Doherty, a história dos modos de expor está intimamente amalgamada à própria história da arte e aos deslocamentos experimentados pela imagem pictórica moderna, finalmente liberada do compromisso com a representação clássica devido, não exclusivamente mas sem dúvida de modo bastante relevante, ao advento de tecnologias de produção e reprodução de imagens.

Ao pensarmos na cronologia que marca o desenvolvimento do cubo branco como forma hegemônica de expor e de ver obras de arte, podemos observar que ela é em larga medida contemporânea do processo de desenvolvimento urbano que culmina nas grandes cidades modernas. No que concerne às imagens, o desenvolvimento urbano e comercial, contemporâneo do desenvolvimento de tecnologias de produção e reprodução de imagens e do campo da publicidade, que então se profissionalizava, culmina na configuração de novos ambientes visuais, como o que podemos observar em grandes avenidas comerciais - dentre as quais, a Times Square em Nova York segue sendo paradigmática (Figura 1) que se assemelham enormemente, com sua profusão de anúncios publicitários, aos já referidos salões de arte, que vigoraram como modelo de exposição de arte até o início do século XX (Figura 3). 


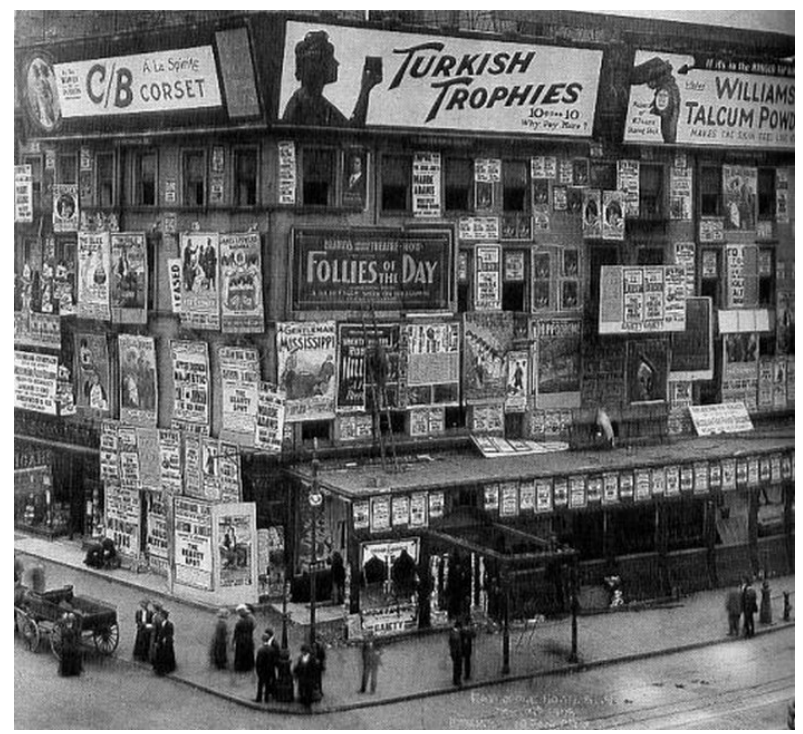

Figura 1: Times Square, Nova York, 1909

Fonte: Charney e Schwartz (2001: 118)

Uma questão que nos parece fundamental, portanto, emerge da complexidade do ecossistema mediático moderno, no qual a imagem reprodutível espraia-se sobre as urbes como uma segunda pele. Neste contexto, um ponto importante parece ter sido negligenciado por grande parte dos estudos que investiram no campo das exposições artísticas, isolando a imagem da arte das demais imagens do mundo: a descontextualização das obras de arte de seu entorno sociocultural e a sublimação da corporalidade talvez sejam efeitos colaterais do cubo branco, e não seus objetivos primordiais. $O$ desenvolvimento do cubo branco parece comprometido com um desejo de chancelar, em meio à profusão das imagens mediáticas, algumas imagens como sendo dignas de uma percepção de tipo bem específico, protegendo as imagens artísticas dos famintos ambientes mediáticos.

Walter Benjamin (1987) observou duas maneiras diferentes de se relacionar com as obras de arte: uma marcada pela distração e a outra marcada pelo recolhimento. O filósofo contrasta estes dois regimes perceptivos afirmando que "quem se recolhe diante de uma obra de arte mergulha dentro dela e nela se dissolve [...]. A massa distraída, pelo contrário, faz a obra de arte mergulhar em si, envolvendo-a com o ritmo de suas vagas, absorve-a em seu fluxo" (BENJAMIN, 1987: 193).

Não parece ser fortuita a analogia feita por O'Doherty entre o espaço expositivo e a igreja medieval. A gramática arquitetural do cubo branco (e sua desconstrução sistemática desde meados do século XX), além de constituir um dos pilares da subjetividade artsy globalizada nos mesmos termos em que os elementos da arquitetura sacra foram fundamentais na comunicação dos valores religiosos em sociedades não letradas, parece fundamental para instauração de um regime perceptivo marcado pelo recolhimento e pelo exame contemplativo das imagens, sobretudo quando, fora dele, as imagens estão por todos os lados. A reprodutibilidade técnica da imagem e sua abundância contemporânea, além de ter tensionado o estatuto de fruição das imagens, criou o que talvez seja um problema - político, institucional e econômico - para o sistema das artes que pode ser pensado, ainda a partir de Walter Benjamin, como a perda de sua aura.

\section{Imagem e valor}

Se um dos efeitos produzidos pelo dispositivo do cubo branco é um convite ao recolhimento e uma sublimação do corpo como condição para uma contemplação atenta das obras de arte, ao observarmos a arquitetura das lojas de luxo contemporâneas (Figura 2) podemos lançar a suspeita de que não é apenas na recepção das obras de arte pelo espectador que o dispositivo do cubo branco reverbera. Não é raro, em grandes centros urbanos e templos do consumo de luxo, 
${ }^{3}$ A série Mr. Selfridge (2016), abrigada pela plataforma Netflix, é baseada na história do americano Harry Gordon Selfridge, criador da loja de departamentos Selfridge's em Londres e considerado um pioneiro na transformação dos modos de consumir na Inglaterra puritana do começo do século XX. Suas vitrines, displays, peças publicitárias e ações promocionais funcionavam como uma espécie de espetáculo no qual os produtos diluíamse em cenários que faziam os clientes sonhar. Também sobre este tema, cf. Rappaport (2001). nos depararmos com vitrines despojadas de excessos ornamentais nas quais já não vemos uma cena nos moldes daquelas que Harry Selfridge montava em sua loja na Oxford Street, em Londres, para fazer sonharem os pedestres ${ }^{3}$, mas um e somente um - produto. Não qualquer produto, uma bolsa Prada, uma caneta Montblanc ou um vestido Christopher Kane, por exemplo.
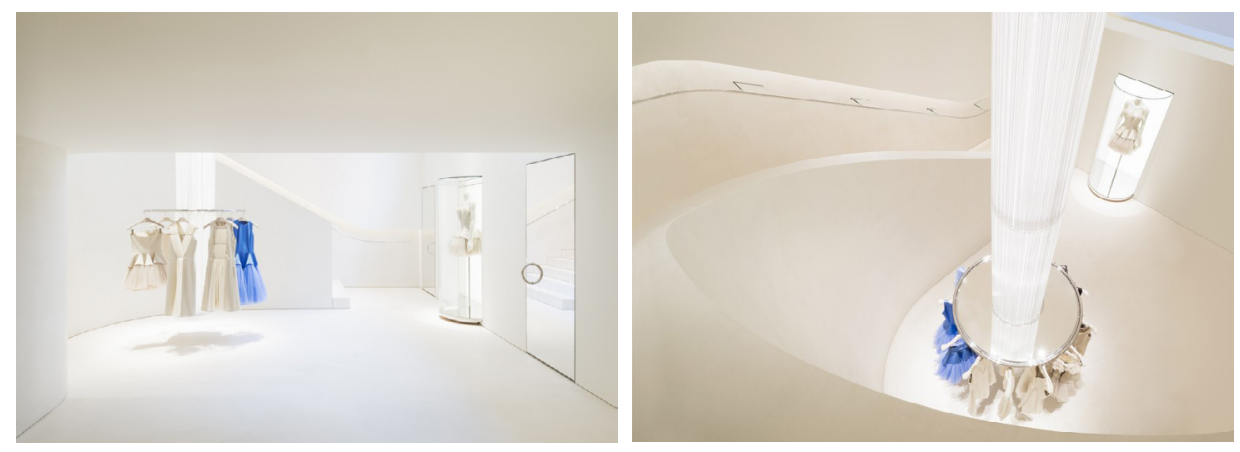

Figura 2: Loja Christopher Kane, Londres, projeto de John Pawson, fotografias de Gilbert McCarragher

Fonte: https://bit.ly/2I2GHUf

O cubo branco, ao descontextualizar o que se encontra exposto em seu interior, através de sua configuração espacial despojada de ornamentos, projeta sobre as obras de arte ou sobre bens de consumo de luxo uma extemporaneidade que acaba por conferir legitimidade cultural a seus estratosféricos preços. A incorporação de tal dispositivo de exposição pelo mercado de luxo sinaliza para nós este efeito, algumas vezes negligenciado nas críticas ao cubo branco, de destemporalização do objeto e de blindagem contra sua potencial desvalorização no contexto de uma economia marcada pela obsolescência programada, pela efemeridade da moda (LIPOVETSKY, 1989) e por uma cultura do descarte (MARDER, 2018).

Benjamin (1987: 170) define aura como sendo "uma figura singular, composta de elementos espaciais e temporais: a aparição única de uma coisa distante por mais perto que ela esteja" e diagnostica, em um de seus fragmentos mais conhecidos, seu declínio. Os dois movimentos que se encontram na gênese do processo de destruição da aura são caros às massas modernas: um desejo de fazer as coisas ficarem "mais próximas" e uma superação do caráter único e irrepetível dos fatos pela reprodutibilidade.

A potência e pertinência do diagnóstico benjaminiano hoje parece encontrar-se menos em uma ratificação da hipótese de uma destruição definitiva da aura do que naquilo que a sintética descrição de sua lógica de funcionamento nos permite ver se deslocando, como placas tectônicas, nas configurações contemporâneas e pós-massivas do capitalismo de consumo. Neste contexto, o cubo branco aparece como sintoma da crise da aura, instaurada pela reprodutibilidade técnica e pela consequente preponderância do valor de exposição sobre o valor de culto, aspecto também elaborado por Benjamin no clássico ensaio $A$ obra de arte na era de sua reprodutibilidade técnica, escrito entre 1935 e 1936. Mas, além de sintoma desta crise, o cubo branco procura resistir a ela e talvez possamos ir além e dizer que ele tenta operar como um dos últimos bastiões da aura.

O modo de expor dos salões do século XIX, ao mesmo tempo em que sublinhava os limites de cada imagem através de suas molduras ricamente ornamentadas, parecia denunciar uma abundância, praticamente incognoscível, de obras únicas. No interior do cubo branco, as obras de arte adquirem a possibilidade de existir individualmente, distanciadas ou mesmo isoladas de outras imagens e, como já indicamos, descontextualizadas histórica, política e socialmente. Em tese, é na galeria de arte ou no museu - e, hoje, talvez também nas lojas de luxo - que esta figura singular e irreprodutível tenta sobreviver. O cubo branco é (ou era) a UTI da aura. 


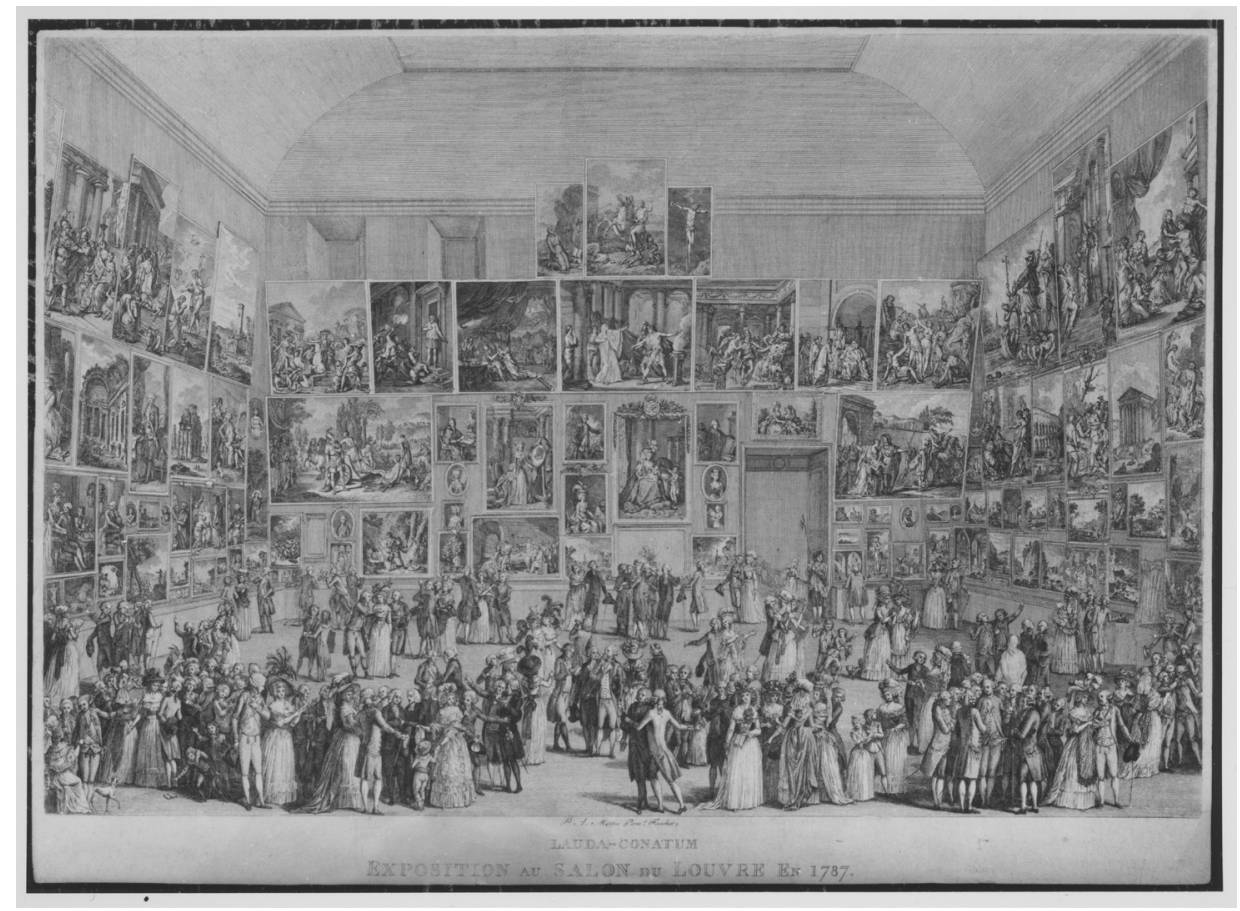

Figura 3: Exposition au Salon de 1787, água-forte de Pietro Antonio Martini (1738-1797) Fonte: https://bit.ly/2yxeyPW

A proliferação de reproduções de obras icônicas da história da arte poderia, há uns poucos anos, colocar por terra a argumentação que construímos até aqui de que o espaço expositivo teria se convertido em um dispositivo comprometido com a manutenção da aura. Mas basta uma visita rápida ao Instagram, filtrada por hashtags criadas por ocasião de alguma exposição, para constatarmos novas inflexões no estatuto das obras de arte. Sendo rigorosos na leitura de Benjamin, precisamos sinalizar a articulação que o autor aponta entre o declínio da aura e a, então emergente, cultura de massas. A necessidade de voltar a esta questão da aura da obra de arte na era do Instagram é, em larga medida, tributária do fato de que a rede social já não pode ser pensada exclusivamente a partir dos elementos que organizavam o consumo de imagens (e por imagens) nas sociedades de massa.

O desenvolvimento e a proliferação de tecnologias de produção, armazenamento e compartilhamento de imagens digitais, associados à atual acessibilidade dos dispositivos inteligentes de comunicação móvel, pulverizaram dentre aqueles que outrora consumiam em massa as imagens a possibilidade de produzir e compartilhar suas próprias imagens, além de consumir um fluxo de imagens organizado sob medida.

Neste contexto, parecem ser cada vez mais frequentes as experiências de espectadores com obras de arte que resultam em registros visuais e/ou audiovisuais deste encontro no ambiente expositivo - seja através de imagens de obras de arte postadas nos perfis da rede social, que corroboram a ideia de que aquela pessoa esteve efetivamente diante de algo único, seja através das controversas selfies, que não deixam nenhuma margem de dúvida e testemunham efetivamente o encontro "corpo a corpo" do usuário da rede social com determinada obra de arte. Estes rastros dos encontros com a arte, estas imagens que se precipitam no fluxo do Instagram, parecem testemunhar, paradoxalmente, o declínio da aura e sua permanência. E nossa aposta é que este paradoxo é amplamente tributário da reconfiguração do ecossistema mediático massivo quando da emergência de interfaces e plataformas que solapam a divisão entre emissor e receptor, em favor deste novo e controverso elemento: o usuário.

Se a televisão, a rádio e a imprensa polarizavam a produção de imagens, agora esta produção encontra-se distribuída entre todos e todas que disponham 
de um telefone com internet e um perfil ativo em alguma rede social (ou em todas elas). Neste sentido, parece que o declínio moderno da aura, associado à reprodutibilidade técnica da imagem única, culminou em um solo fértil, no contexto pós-massivo, para uma ressurreição ou transfiguração da aura. As imagens artísticas consumidas massivamente constituíram um repertório comum a partir do qual se reconhece a excepcionalidade de um encontro com algo único e original. As fotografias e as selfies diante de obras icônicas como, por exemplo, O beijo, uma das telas mais famosas de Gustav Klimt, ao mesmo tempo em que parecem apontar para uma experiência que já não é exclusivamente marcada pelo recolhimento e pela contemplação, parecem alinhar-se a uma espécie de consenso construído histórica, cultural e institucionalmente, mas alimentado também pela própria lógica da reprodutibilidade técnica - a respeito da excepcionalidade do encontro com a obra "original". Poderíamos, nestes casos, argumentar que se trata de uma exposição do culto?

\section{A aura instagramável?}

A ostensiva prática de produção de fotografias e selfies em exposições de arte tem sido tema de uma série de debates entre os profissionais de museus e galerias de arte em todo o mundo. Diante de um cenário no qual as métricas de avaliação que asseguram a continuidade das atividades de instituições culturais públicas e privadas são reduzidas à quantidade de visitantes e ao impacto de seus programas nas redes sociais, medidas como as adotadas pelo Museu do Vaticano, que interdita fotografias no interior da Capela Sistina através de um policiamento ostensivo (quase tão incômodo quanto os grandes grupos de turistas-fotógrafos que se aglomeram diante de obras-primas nos museus franceses), tornam-se cada vez mais raras.

Nesta disputa institucional por financiamento, uma das formas de acolhimento deste novo regime de relação com a arte, mediado pelas telas de telefones celulares, consiste na criação de espaços instagramáveis anexos às exposições. No contexto de uma grande retrospectiva de Edward Hopper no Palazzo Reale, em Milão, no já longínquo ano de 2010, ano de lançamento do Instagram, o curador Carter Foster incluiu na mostra a instalação interativa Friday, 28th August 1952, 6 a.m., New York, do artista austríaco Gustav Deutsch (Figura 4). Em um espaço adjacente à grande retrospectiva, o artista reproduziu a cenografia do quadro Morning sun, pintado por Hopper em 1952 em uma espécie de estúdio. Deste modo, o espectador pôde ingressar no mundo de Hopper e se tornar protagonista desta icônica cena.

O título da instalação Friday, 28th August 1952, 6 a.m., New York afina-se com a própria poética de Hopper, provavelmente o mais importante pintor realista americano do século XX, cuja obra foi pensada, não poucas vezes, a partir de suas relações com uma estética cara ao instantâneo fotográfico. As composições de Hopper abordam o tema da solidão, através de imagens extraídas do cotidiano de cidades americanas. A instalação de Deutsch tensiona a temporalidade da pintura ao registrar, com uma câmera fixa, os deslocamentos dos visitantes no interior do cenário da pintura de Hopper. Estes registros em vídeo são exibidos como parte da instalação, em um televisor. A instalação é composta de modo a evidenciar os protocolos subjacentes à estética realista. O cenário é montado orientado para uma câmera fixa, posicionada de modo a capturar o ponto de vista idêntico àquele que vemos retratado na pintura de Hopper. Deste modo, o visitante da exposição pode percorrer o espaço visto na representação pictórica de Hopper. 

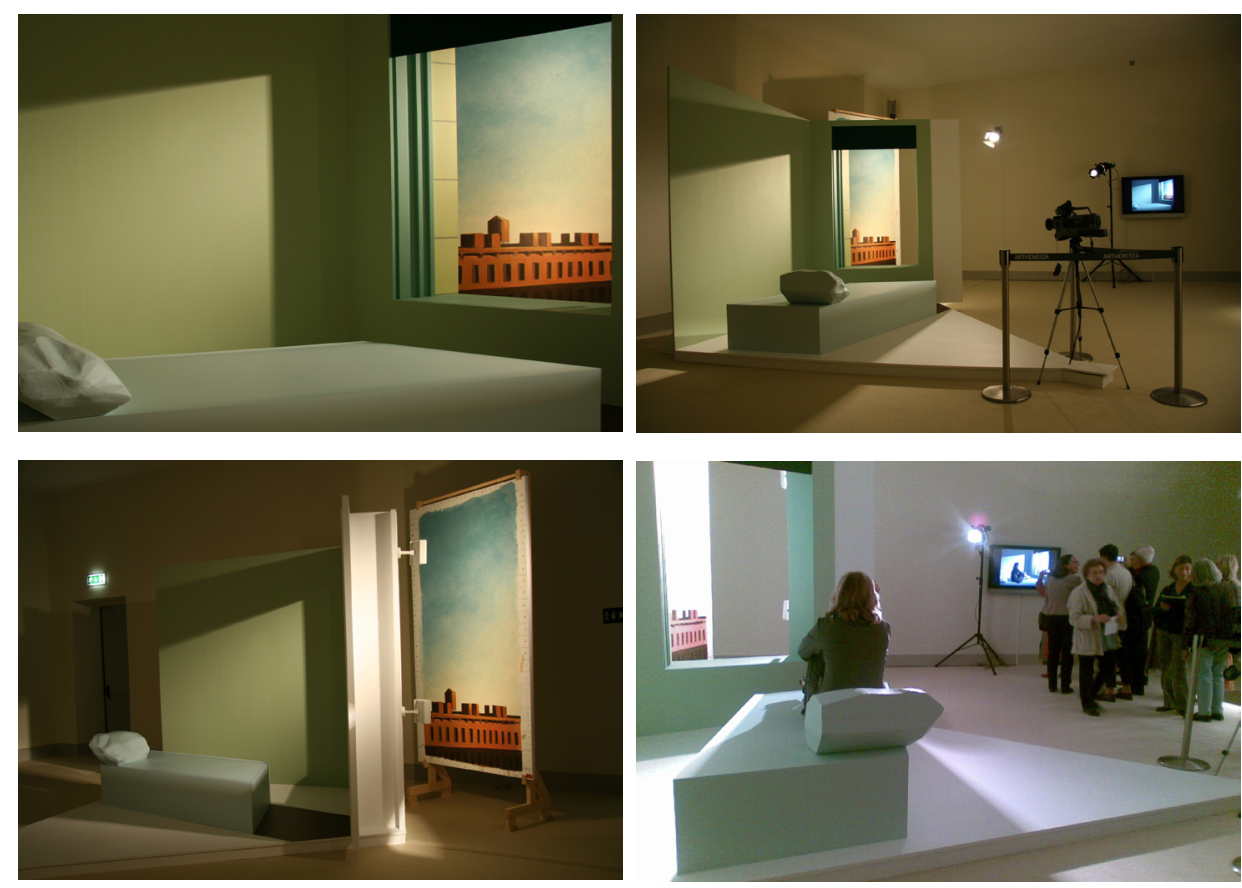

Figura 4: Vistas da instalação "Friday, 28th August 1952, 6 a.m., New York", de Gustav Deutsch, Palazzo Reale, Milão, 2010

Fonte: https://bit.ly/2YDvQ9n

Nesta instalação, concebida e exposta em um contexto pré-Instagram, a articulação entre espaço, tempo e corporalidade adquire um estatuto diferente daquele em operação no dispositivo do cubo branco. Deutsch temporaliza a experiência da obra lançando mão dos tableaux vivants, torna explícita toda a artificialidade envolvida em uma configuração espacial orientada para a câmera e reinsere o corpo do espectador no centro do trabalho. Mas esta aparente reintegração da corporalidade no circuito de fruição da obra precisa ser nuançada, pois já não parece se tratar de um investimento na experiência proprioceptiva como fonte de produção de sentido, mas de um prenúncio da emergência de um corpo-imagem, que vem se radicalizando com a popularização do Instagram nos últimos anos.

A instalação de Deutsch poderia ser lida à luz da tese benjaminiana de que "uma das tarefas mais importantes da arte foi sempre a de gerar uma demanda cujo atendimento integral só poderia produzir-se mais tarde" (BENJAMIN, 1987: 190). No ano em que surgia o Instagram, o artista austríaco antecipava um modo de ver que somente alguns anos depois, com a popularização do aplicativo, se tornaria hegemônico. Na Figura 4D podemos observar como a solidão, tematizada por Hopper em suas pinturas, atualizase neste ecossistema de imagens mediáticas. No dispositivo criado por Deutsch, o visitante que ingressa no cenário da pintura de Hopper não tem a possibilidade de se ver como parte da cena. O realismo da pintura só se reconstrói sob a forma de uma imagem videográfica que é exibida em um televisor instalado na parede adjacente ao cenário. Os olhares dos demais visitantes da instalação parecem ser capturados pela tela e a visitante que se encontra no centro da cena parece experimentar uma solidão que tem, como revés, a visibilidade de sua imagem.

O contexto prenunciado por Deutsch pode ser observado no comportamento de visitantes e mediadores em determinadas exposições extremamente populares contemporaneamente, como as da artista japonesa Yayoi Kusama. Percebemos, nas exposições de Kusama, que um pacto parece ter se estabelecido entre as instituições e o público no que diz respeito à centralidade do registro fotográfico, digital e compartilhável, na relação com suas obras. O ritmo da visita e, portanto, a articulação entre o tempo de fruição e o espaço percorrido, já não é mais orientado nem em função dos olhos que escrutinam e contemplam, nem do corpo que se deixa imergir nas vertiginosas instalações da artista japonesa. É o instante do clique fotográfico que marca o compasso dos deslocamentos dos 
corpos-imagens entre os ambientes espelhados da artista que, a despeito de sua longa e consistente trajetória e da bela articulação que criou entre os espelhos e o infinito, tornou-se um verdadeiro fenômeno da cultura dos selfies.

\section{Considerações finais}

Não foi nossa pretenção, neste breve ensaio, celebrar ou condenar as transformações que contemporaneamente reverberam nos modos como experimentamos o espaço, o tempo e nosso próprio corpo quando visitamos uma exposição de arte. A arte frequentemente foi reivindicada a partir de uma suposta suspensão nos esquemas perceptivos cotidianos, uma brecha através da qual a sensibilidade poderia quebrar os grilhões que pesam sobre nossa percepção. Nas ideias e exemplos que apresentamos aqui, entretanto, ficou patente que as mediações que permeiam nosso contato com as obras de arte repercutem tanto na nossa percepção enquanto visitantes de exposições de arte quanto em todo o processo de valoração crítica e monetária que constitui o sistema da arte.

Neste sentido, afinamo-nos tanto com os gestos que podemos remeter às teorias da mídia alemãs, quanto com a recente aparição de um domínio no interior da história da arte dedicado às histórias das exposições. A heterogeneidade dos elementos que confluem e concorrem no momento do encontro de uma pessoa com uma obra de arte resulta em um contexto de elevada complexidade, que já faz - e seguirá, por ora, fazendo - correr muita tinta. E o que há de fascinante em tudo isso é que, a despeito de todos os esforços - arquitetônicos, tecnológicos, institucionais e financeiros - de colonização de nossos corpos e de nossa percepção, parece ainda haver brechas que fazem com que, vez ou outra, saiamos transformados de uma exposição. Mesmo que se trate de uma exposição no cubo branco, mesmo que ela tenha deixado seus rastros em nosso Instagram.

\section{Referências}

BAITELLO JR., N. A era da iconofagia: reflexões sobre imagem, comunicação, mídia e cultura. São Paulo: Paulus, 2014.

BAITELLO JR., N. A carta, o abismo, o beijo: os ambientes de imagens entre o artístico e o mediático. São Paulo: Paulus, 2018.

BELTING, H. O fim da história da arte: uma revisão dez anos depois. São Paulo: Cosac Naify, 2012.

BELTING, H. Antropologia da imagem. Lisboa: KKYM, 2014.

BENJAMIN, W. Magia e técnica, arte e política: ensaios sobre literatura e história da cultura. São Paulo: Brasiliense, 1987. (Obras escolhidas v. 1).

CHARNEY, L.; SCHWARTZ, V. R. O cinema e a invenção da vida moderna. São Paulo: Cosac \& Naify, 2001.

CYPRIANO, F.; OLIVEIRA, M. M. Histórias das exposições: casos exemplares. São Paulo: Educ, 2017.

GUMBRECHT, H. U. Produção de presença: o que o sentido não consegue transmitir. Rio de Janeiro: Contraponto: Ed. PUC-Rio, 2010.

LAFUENTE, P. et al. A história das "histórias das exposições" por Pablo Lafuente: Entrevista por Fabio Cypriano e Mirtes Marins de Oliveira. In: CYPRIANO, F.; OLIVEIRA, M. M. Histórias das exposições: casos exemplares. São Paulo: Educ, 2017, p. 13-37. 
LIPOVETSKY, G. O império do efêmero: a moda e seu destino nas sociedades modernas. São Paulo: Companhia das Letras, 1989.

MARDER, M. Lixeiranomia. Comunicação, Mídia e Consumo, São Paulo, v. 15, n. 44, p. 10-26, 2018.

MÜLLER, A.; FELINTO, E. Medialidade: encontros entre os estudos literários e os estudos de mídia. Contracampo, Niterói, v. 19, p. 125-136, 2008.

O'DOHERTY, B. Inside the white cube: l'ideologia dello spazio espositivo. Monza: Johan \& Levi Editore, 2012.

RAPPAPORT, E. D. "Uma nova era de compras": a promoção do prazer feminino no West End londrino, 1909-1914. In: CHARNEY, L.; SCHWARTZ, V. R. O cinema e a invenção da vida moderna. São Paulo: Cosac \& Naify, 2001. p. 187-221.

SANTOS, K. C. H. O. Estudos dos conceitos fundamentais da teoria da mídia de Harry Pross: uma teoria dos multimeios. 2009. Monografia de conclusão do curso (Bacharelado em Comunicação e Multimeios) - Pontifícia Universidade Católica de São Paulo, São Paulo, 2009. 